\title{
Sıvı Nitrojende Depolanan Ephestia kuehniella Zell. Yumurtalarında Trichogramma evanescens Westwood ve Trichogramma brassicae Bezdenko Türlerinin Kitle Üretimlerinin Araştırılması
}

Mass Production of Trichogramma evanescens Westwood and Trichogramma brassicae Bezdenko Using Ephestia kuehniella Zell. Eggs Stored in Liquid Nitrogen

\author{
Şennur BAŞÜĞÜT ${ }^{1}$, Nihal ÖZDER ${ }^{2 *}$
}

\section{Özet}

Biyolojik kontrol amacıyla Türkiye'de çalışılan birçok parazitoid türü vardır. Trichogrammatidae familyası da bunlar arasındadır. Trichogramma türleri, bitkilerde zararlı olan Lepidoptera takımının yumurtalarına karşı özellikle kullanılmaktadır. Bitkilere zarar vermeden, zararlıyı henüz yumurta halindeyken öldürür. Trichogramma cinsine ait türler, böcek yetiştirme odalarında seri üretim ve salım kolaylığı nedeniyle biyolojik kontrolde özel bir öneme sahiptir. Trichogramma'ların kitle üretiminde konukçu yumurtasının sıvı azot içinde depolanması, alternatif bir yöntem olabilir. Bu çalışmanın amacı, dondurulmuş Ephestia kuehniella Zell yumurtalarını farklı zamanlarda depolayıp Trichogramma evanescens Westwood ve Trichogramma brassicae Bezdenko türlerinin parazitleme potansiyellerini belirleyerek daha bol, kolay ve ucuz üretimleri araştırılmıştır. Bu çalışmada, Ephestia kuehniella Zell. (Un güvesi) yumurtaları sivı nitrojende $\left(-196^{\circ} \mathrm{C}\right)$ farklı sürelerde $(1,2,3,4,5$ ve 6 hafta boyunca) depolanmıştır. Ephestia kuehniella Zell'in yumurtaları depolandıktan sonra, Trichogramma evanescens Westwood ve Trichogramma brassicae Bezdenko türlerinin parazitleme performansları, bu parazitlenmiş yumurtalardaki yetişkinlerin cinsiyet oranı ve parazitlenen yumurtalardan elde edilen dişilerin ömürleri belirlenmiştir. Depodan çıkarılan Ephestia kuehniella Zell. yumurtalarını Trichogramma evanescens Westwood ve Trichogramma brassicae Bezdenko türlerinin parazitleme performansı incelendikten sonra depolanmış yumurtalardan elde edilen dişilerin kitle üretimindeki performansı araştırılmıştır. Çalışmalar $25 \pm 1^{\circ} \mathrm{C}$ sıcaklıkta $\% 60-70$ orantılı nemde 16 aydınlık 8 saat karanlık koşullarda yürütülmüştür. Araştırmanın sonucunda, 5 hafta süre ile sıvı azotta depolanmış E. kuehniella yumurtalarının Trichogramma evanescens Westwood ve Trichogramma brassicae Bezdenko tarafından başarılı bir şekilde parazitlenebildiği, 6 hafta süre ile depolanmış yumurtalarda parazitlemenin hiç gerçekleşmediği saptanmıştır. Ancak her iki tür içinde hem sıvı azotta depolanmış E. kuehniella yumurtalarının parazitlenme sayısı, açılma sayısı ve dişi sayısı hem de sıvı azotta depolanmış yumurtalardan elde edilen dişi parazitoitlerin performansı açısından, 3 hafta depolama süresinin en uygun süre olduğu saptanmıştır.

Anahtar Kelimeler: Trichogramma evanescens, Trichogramma brassicae, Ephestia kuehniella, Sivı nitrojen, Kitle üretimi.

\footnotetext{
${ }^{1}$ Şennur BAŞÜĞÜT, Babaeski Ticaret Borsas1, Toprak ve Yaprak Analiz Laboratuvarı, Kırklareli. Türkiye. E-mail: sennurbasugut@gmail.com (iD OrcID: 00000002-2465-0679.

2*Sorumlu Yazar/Corresponding Author: Nihal ÖZDER, Tekirdağ Namık Kemal Üniversitesi, Ziraat Fakültesi, Bitki Koruma Bölümü, Tekirdağ. Türkiye Email: nozder@nku.edu.tr OrcID: 0000-0002-4637-5364

Atıf/Citation: Şennur BAŞÜĞÜT, Nihal ÖZDER. Sıvı Nitrojende Depolanan Ephestia kuehniella Zell. Yumurtalarında Trichogramma evanescens Westwood Ve Trichogramma brassicae Bezdenko Türlerinin Kitle Üretimlerinin Araştırılması. Tekirdağ Ziraat Fakültesi Dergisi, 17 (3), $292-303$.

*Bu çalışma Yüksek Lisans tezinden özetlenmiştir.

CBu çalışma Tekirdağ Namık Kemal Üniversitesi tarafından Creative Commons Lisansı (https://creativecommons.org/licenses/by-nc/4.0/)

kapsamında yayınlanmıştır. Tekirdağ 2020
} 


\begin{abstract}
For the purpose of biological control there are many parasitoid species studied in Turkey. Species included in the family Trichogrammatidae are also among these. Trichogramma species are particularly successful on the eggs of members of the Lepidoptera team, which are harmful in plants. Without causing damage to pests in plants, it kills while they are in the egg state. Trichogramma species have a special importance in biological control due to the ease of mass production and release in insect breeding chambers. The storage of host eggs in liquid nitrogen may represent an alternative method in the mass production of Trichogramma. The aim of this study was to determine the parasitic potential of Trichogramma evanescens Westwood and Trichogramma brassicae Bezdenko species of Ephestia kuehniella Zell eggs stored at different times at and the availability of frozen embryo frozen E. kuehniella eggs to provide easier, cheaper and more abundant production of egg parasitoid Trichogramma species were investigated. The aim of this study was to determine the parasitic potential of Trichogramma evanescens Westwood and Trichogramma brassicae Bezdenko species of Ephestia kuehniella Zell eggs stored at different times at and the availability of frozen embryo frozen E. kuehniella eggs to provide easier, cheaper and more abundant production of egg parasitoid Trichogramma species were investigated. In this study, Ephestia kuehniella Zell. (Flour moth) eggs were stored in liquid nitrogen $\left(-196^{\circ} \mathrm{C}\right)$ for at different times $(1,2,3,4,5$ and 6 weeks). Ephestia kuehniella Zell removed from the warehouse. After examining parasitic performance of Trichogramma evanescens Westwood and Trichogramma brassicae Bezdenko species, the eggs of Ephestia kuehniella Zell were collected from warehouse, the sex ratio of the adults female from these parasitized eggs were examined and the longevity of the females and the number of eggs parasified during their lifetime were determined.After examining parasitic performance of Trichogramma evanescens Westwood and Trichogramma brassicae Bezdenko species, their performance in mass production of stored eggs were investigated. The studies were carried out for 16 hours for 8 hours in dark conditions at $60-70 \%$ humidity at $25 \pm 1{ }^{\circ} \mathrm{C}$. As a result of the study, it was found that $E$. kuehniella eggs stored in liquid nitrogen for 5 weeks can be successfully parasitized by Trichogramma evanescens Westwood and Trichogramma brassicae Bezdenko, and no parasites have been observed in stored eggs for 6 weeks. However, in both species, it was determined that 3 weeks were the most suitable time for storage, both in terms of parasitic number, opening number and number of females of $E$. kuehniella eggs stored in liquid nitrogen and in the performance of female parasitoids obtained from eggs stored in liquid nitrogen.
\end{abstract}

Keywords: Trichogramma evanescens, Trichogramma brassicae, Ephestia kuehniella, Liquit nitrogen, Mass producti 


\section{Giriş}

Türkiye'de biyolojik mücadele amacıyla üzerinde çalışılan pek çok parazitoit tür vardır. Trichogrammatidae familyasına bağlı türlerde bunlar arasındadır. Trichogramma türleri üzerinde genellikle kitle üretiminde kullanılacak uygun konukçunun belirlenmesi, uygun konukçu yumurtası yaşının belirlenmesi, düşük sıcaklıklara sahip depolama koşullarında konukçu yumurtalarında parazitoitlerin kitle üretimi, parazitlenmiş yumurtaların farklı sıcaklıklarda depolanması ve sıvı azotta depolanmış un güvesi yumurtalarında kitle üretimi gibi çalışmalar yürütülmüştür (Bulut, 1990; Jajali ve Singh, 1992; Özder, 2004; Lohmann ve ark. 2007; Yaz ve Özder 2016; Özder ve Tayat, 2018).

$\mathrm{Bu}$ çalışmada ise, Ephestia kuehniella Zell. (Un güvesi) yumurtaları sıvı nitrojende $\left(-196^{\circ} \mathrm{C}\right)$ farklı sürelerde 1, 2, 3, 4, 5 ve 6 hafta boyunca depolanmıştır. Depodan çıkarılan Ephestia kuehniella Zell. yumurtalarını Trichogramma evanescens Westwood ve Trichogramma brassicae Bezdenko türlerinin parazitleme performans1 incelendikten sonra parazitlenen bu yumurtalardan çıkan erginlerin cinsiyet dağılımına bakılıp, dişilerin ömür uzunlukları ile ömrü boyunca parazitledikleri günlük yumurta sayıları saptanarak, Trichogramma türlerinin daha kolay, ucuz ve bol üretimini sağlayabilmek için embriyosu dondurulmuş E. kuehniella yumurtalarının kullanılabilirliği araştırılmıştır.

\section{Materyal ve Metot}

\subsection{Materyal}

Araştırmanın ana materyalini yumurta parazitoitleri Trichogramma evanescens Westwood, Trichogramma brassicae Bezdenko ve konukçusu Ephestia kuehniella Zell. oluşturmaktadır. Kullanılan diğer materyaller ise cam tüpler, yumuşak uçlu firçalar, bal, beyaz kağıt, plastik küvet, plastik yumurtlama kapları, \%10’luk arap zamkı, pamuk, makas, misır kırması, un ve kepektir.

Araştırmanın ana materyalleri olan Ephestia kuehniella ve parazitoitler Trichogramma evanescens Westwood ve T. brassicae Bezdenko Namık Kemal Üniversitesi, Ziraat Fakültesi Bitki Koruma Bölümünde yetiştirilmekte olan kültürlerden elde edilmiştir.

\section{Metot}

\subsection{Konukçu Ephestia kuehniella'nın üretimi}

Un güvesinin üretimi $25 \pm 1{ }^{\circ} \mathrm{C}$ sıcaklıkta, \%60-70 oransal nemde 16 saat aydınlık-8 saat karanlık koşulların sağlandığ 1 iklimlendirme odasında gerçekleştirilmiştir. Üretim için un, kepek ve mısır kırması 2:1:1 oranında hazırlanarak, karışımdaki dış bulaşmaları önlemek amacıyla $60^{\circ} \mathrm{C}$ sıcaklığa ayarlı etüvde 5 saat bırakılarak steril hale getirilmiştir. Yetiştirmede kullanılan diğer materyaller (plastik kaplar, firçalar, yumurtlama kafesleri, küvetler vb.) \%1'lik sodyum hipoklorit ile dezenfekte edilerek kullanılmıştır. Dezenfekte edilen kapaklı un güvesi yetiştirme kapları içerisine; steril un, kepek kırma karışımı alınarak üzerine daha önceki kültürlerden elde edilen E. kuehniella yumurtaları ekilmiştir. Daha sonra kaplarının kapakları kapatılarak kitle üretim odasında gelişmeye bırakılmıştır. Gelişimini tamamlayıp ergin hale gelen E. kuehniella'lar vakumlu pompa ile toplanarak yumurtlama kaplarına yerleştirilmiştir. Bu kaplardan günlük olarak toplanan yumurtaların bir kısmı deneme için kullanılmıştır. Geriye kalan kısmıda kültürün devamını sağlamak amacıyla un, kepek ve mısır kırması karışımına ilave edilerek yeni kültürler açılmıştır (Bulut ve Kılınçer, 1987; Özder, 2004).

\subsection{Parazitoit Trichogramma evanescens ve Trichogramma brassicae'nın üretimi}

Parazitoit Trichogramma evanescens Westwood ve T. brassicae Bezdenko $25 \pm 1^{\circ} \mathrm{C}$ sicaklık, \%60-70 oransal nem 16 saat aydınlık, 8 saat karanlık koşulların sağlandığı iklim odasında ve E. kuehniella kültüründen sağlanan yumurtalar üzerinde yetiştirilmiştir (Özder, 2004). E. kuehniella'nın üretimi sırasında günlük olarak toplanan yumurtaların bir kısmı, o günün tarihi yazılı olan şeritler halindeki beyaz kağıtlar üzerine, arap zamkı yardımıyla dikkatli bir şekilde yapıştırılmış ve ergin parazitoitlerin beslenmesi için sulandırılmış bal damlatılarak içerisinde genellikle yeni çıkmış ergin parazitoitlerin bulunduğu cam tüplere $(1.7 \times 18 \mathrm{~cm})$, yumurtalara zarar vermeden ve tüp içerisindeki parazitoitleri kaçırmadan pens aracılığıyla yerleştirilmiş. Tüplerin ağız kısmı pamukla kapatılmıştır. Böceklerin ışı̆ga yönelim davranışından faydalanılarak, günlük yumurtanın bulunduğu şeritler 
aydınlık olacak şekilde tüplerin diğer kısımları karartılmıştır. Parazitleme işlemi gerçekleştikten ortalama 3-4 gün sonra embriyo gelişiminden kaynaklı kararmalar meydana gelmiştir. Parazitlenmeyen yumurtalar kağıtlardan uzaklaştırılarak aynı tür tarafından aynı tarihte çıkış yapması öngörülen parazitlenmiş yumurtalar aynı tüp içerisine alınmıştır. Konukçu yumurtası içerisinde pupa evresini tamamlayan parazitoit kendisine yumurta üzerinde yuvarlak bir çıkış deliği açarak ergin çıkışını gerçekleştirmiştir. Denemenin kurulacağı tarihte çıkış yapanlar deneme için kullanılmış, diğer erginlerle ise aynı işlemler tekrarlanarak üretimin devamlılığı sağlanmıştır.

\subsection{Biyolojik çalış̧malar}

Her gün kontrol edilerek toplanan taze E. kuehniella yumurtaları, eppendorf tüpler $(5 \mathrm{ml})$ içine yerleştirildikten sonra alüminyum folyo ile sarılarak, konik tüplere $(50 \mathrm{ml})$ yerleştirilerek azot tankına $\left(-196^{\circ} \mathrm{C}\right)$ konulmuştur. Tanka yerleştirilen yumurtalar 1, 2, 3, 4, 5 ve 6 hafta süre ile depolanmıştır. Her depolama süresi sonrasında azot tankından çıkarılan tüpler plastik kutu içine aktarılarak 24 saat buzdolabında bekletilmiştir. Depolanmış olan bu yumurtalardan 100'er adedi kağıt şeritlere arap zamkı yardımıyla yapıştırılıp parazitoite besin olması için, bir damla sulandırılmış bal damlatılarak, cam tüplere yerleştirilmiştir. Cam tüplere birer adet çiftleşmiş bir günlük dişi Trichogramma evanescens Westwood salınmıştır. Aynı işlemler Trichogramma brassicae Bezdenko türü içinde gerçekleştirilmiştir. Dişiler 24 saat sonra tüplerden uzaklaştırılmıştır. Her gün yapılan incelemeler ile parazitlenen yumurtaların kararma süresi, parazitlenen yumurta sayısı, parazitlenen yumurtaların açılma süresi ve içlerinden çıkan bireylerin dişi sayısı not edilmiştir. Embriyosu donuk olarak parazitlenmiş yumurtalardan çıkış yapan çiftleşmiş dişi tüplere alınıp ömürleri süresince her gün taze E. kuehniella yumurtası verilerek depolanmış yumurtalardan elde edilen parazitoitlerin performansları incelenmiştir (Krechemer ve Foerster 2016; Özder ve Tayat, 2018).

\section{4. İstatistiki değerlendirme}

Denemeler 10 tekerrürlü olarak Tesadüf Parselleri Deneme Desenine göre yürütülmüştür. Denemelerden elde edilen veriler SPSS 25.0 paket programıyla, Duncan Çoklu Karşılaştırma Testine göre değerlendirilmiştir.

\section{Araștırma Sonuçları ve Tartıșma}

\subsection{Depolanmıs E. kuehniella Yumurtalarında Parazitoitlerin Performansı}

\subsection{Parazitlenen yumurtaların kararma süresi}

Trichogramma evanescens tarafindan parazitlenmiş yumurtalardan en kısa sürede kararan $3.70 \pm 0.15$ gün ile 3 hafta

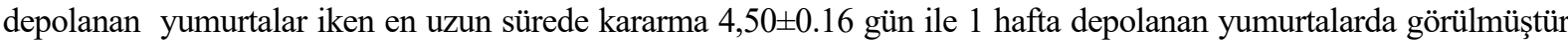
(Çizelge 1). Trichogramma brassicae tarafindan parazitlenmiş yumurtalardan en kısa sürede kararan $3.40 \pm 0.13$ gün ile 3 hafta depolanan yumurtalarken en uzun sürede kararanlar $4.60 \pm 0.16$ gün ile 1 hafta ve $4.40 \pm 0.16$ gün ile $4-5$ hafta depolanan yumurtalar olup aralarında istatistiksel olarak fark bulunamamıștır. (Çizelge 2). Her iki türde de 6 hafta azot tankında depolanmış yumurtalarda hiç kararma görülmemiştir( $\mathrm{p}<0.05)$.

Ay (1994) E. kuehniella yumurtaların $-20^{\circ} \mathrm{C}$ sicaklıkta derin dondurucuda $60 \mathrm{dk}$ ve $120 \mathrm{dk}$ beklettikten sonra $T$. turkeiensis ve T. embryophagum türlerinin parazitlemesine bıraktı̆̆ı çalışmada iki türünde parazitlediği yumurtaların kararma sürelerinin ortalama 5 gün olduğunu belirtmiştir.

Kara (2006) E. kuehniella ve C. cautella yumurtalarınının T. evanescens, T. brassicae, T. cacoeciae türleri tarafindan parazitlendikten sonra genel olarak ortam sıcaklığı arttıkça kararma süresinin kısaldığını bildirmiştir. Güven (2008) ise C. cautella yumurtaların $+4^{\circ} \mathrm{C}^{\prime}$ de $1,2,3$ ve 4 hafta depoladıktan sonra T. evanescens, $T$. brassicae, $T$. cacoeciae türlerine parazitletmiş, parazitlenen bu yumurtalardan $+4^{\circ} \mathrm{C}$ ' de depolama süresi arttıkça kararma sürelerinin uzadığını ve türler arasında fark olmadığını bildirmiştir.

\subsection{Parazitlenen yumurta saytsl}

T. evanescens türünün $-196^{\circ} \mathrm{C}$ 'de depolanan E. kuehniella yumurtalarını parazitleme sayılarının kontrolden farklı olduğu gözlemlenmiş̧tir. $T$. evanescens ergin dişileri en çok 3 hafta depolanan yumurtaları parazitlemişlerdir. Depolanan tüm yumurtalardan sadece 6 hafta depolanan yumurtalarda hiç parazitlenme meydana gelmemiştir. En düşük parazitlenmenin 1, 4 ve 5 hafta depolanan yumurtalar da olduğu görülmüştür (Tablo 1). T. brassicae'nın en yüksek sayıda parazitlemeyi 3 hafta süre ile depolananlarda $35.70 \pm 0 . .96$ adet olarak gerçekleştirdiği saptanmıştır. 3 
hafta boyunca depolanan yumurtaların, 2 hafta depolanan yumurtalarla (34.10 1.07$)$ arasındaki farkın önemsiz olduğu belirlenmiştir. En az parazitlenen yumurtaların ise $20.40 \pm 1.68$ adet ile 1 hafta süreyle depolanan yumurtalar olduğu tespit edilmiştir ( $<<0.05$, Tablo 2).

Krechemer ve Foerster (2016) Mythimna sequax yumurtalarını 30, 60 ve 90 gün boyunca sıvı nitrojende depolamış ve bu yumurtaları, Trichogramma pretiosum türünün aynı oranda parazitlediğini bildirmiş̧tir.

Lohmann vd. (2007) Trichogramma pretiosum'un kitle üretimi için E. kuehniella yumurtalarını sıvı azotta 1, 3, 6 ve 9 ay depolayarak parazitlenme durumunu araştırmışlardır. Sonuç olarak, hiç bir depolama süresinde parazitlenme görülmediğini bildirmişlerdir. Benzer şekilde St-Onge vd. (2016) Trichogramma ostriniae'nın üretimi için, E. kuehniella yumurtalarını sıvı azotta depolamış ve sıvı azotta depolanan yumurtalarda parazitlenme görülmediği için bu depolama yönteminin yumurtaların korunması için uygun bir yöntem olmadığını öne sürmüştür. Bu iki çalışma 6 hafta depolanan yumurtaların parazitlenmemesini destekler niteliktedir.

Greco ve Stilinovic (1998) Sitotroga cerealella yumurtalarını, sıvı nitrojende 20, 30 ve 130 gün depoladıktan sonra T. pretiosum'un parazitleme performansını incelemiş ve 20,30, 130 gün depolanan yumurtaların parazitlenme yüzdesinde istatiksel olarak önemli farklar olmadığını belirtmiştir.

Özder (2002) Trichogramma cacoeciae, T. brassicae ve T. evanescens türlerinin üretimini, $-20^{\circ} \mathrm{C}$ 'de (derin dondurucuda) 1, 2 ve 3 saat depoladığı E. kuehniella yumurtaları üzerinde gerçekleştirerek depolama saatinin arttıkça parazitlenme oranının azaldığını türler arasında parazitlenme oranı bakımından farklılık görülmediğini bildirmiş̧tir. Aynı araştıııc, 2004 yılında yürüttüğü çalışmada $0^{\circ} \mathrm{C}, 4^{\circ} \mathrm{C}$ ve $8^{\circ} \mathrm{C}$ 'de 31 güne kadar depoladığı E. kuehniella yumurtalarından, $T$. cacoeciae'nin en çok tercih etttiği yumurtaların $0^{\circ} \mathrm{C}^{\prime}$ de depolananlar, en az tercih ettiğinin ise $8^{\circ} \mathrm{C}$ 'de depolananlar olduğunu bildirmiştir (Özder,2004).

Güven (2008) 4 ve $8^{\circ} \mathrm{C}$ 'de 1, 2, 3, 4 hafta depoladığı Cadra cautella yumurtalarında Trichogramma sp.'nin kitle üretimini araştırmış ve iki sıcaklıkta da en fazla 1 hafta en az 4 hafta depolanan yumurtaların parazitlendiğini depolama süresi arttıkça parazitlenme oranının azaldığını tespit etmiş̧tir.

Özder ve Tayat (2018) sıvı nitrojende farklı sürelerde depoladıkları E. kuehniella yumurtalarına 2 farklı çözünme yöntemi (su banyosu, buzdolabında bekletme) uyguladıktan sonra bu yumurtalar üzerinde $T$. pintoi'nin kitle üretimini araştırmışlardır. Her iki yöntemde de parazitlenme oranının 3 haftaya kadar depolanan yumurtalarda \%80'nin üzerinde olduğu ve depolama süresi arttıkça parazitlenen yumurta sayısının düştüğünü ve 6 hafta depolanıp su banyosunda çözdürülen yumurtaların \%43 oranında parazitlendiğini belirlemişlerdir.

\subsection{Parazitlenen yumurtaların açılma süresi}

T. evanescens tarafindan parazitlenmiş yumurtaların açılma sürelerinin $8.80 \pm 0.13$ ve $9.20 \pm 0.20$ gün ile 3 ve 2 hafta depolanmış yumurtalarda en kısa olduğu saptanmıştır. 4, 5 ve 1 hafta depolanmış yumurtalardan erginlerin çıkış süresileri arasındaki fark önemsiz bulunmuştur (Tablo 1). T. brassicae'nın parazitlemiş olduğu depolanmış yumurtaların açılma süresi 3, 2 ve 4 hafta depolanmış yumurtalarda sırasıyla 9.30 $0.15,9.50 \pm 0.22,9.60 \pm 0.16$ gün olup en kısa sürede açılmışlardır. En uzun sürede açılan yumurtalar ise aralarındaki fark önemsiz olup $10.70 \pm 0.21$, $10.40 \pm 0.16$ gün ile 1 ve 5 hafta depolanmış yumurtalar olarak tespit edilmiştir ( $\mathrm{p}<0.05$, Tablo 2).

Krechemer ve Foerster (2016) sıvı azotta 30, 60 ve 90 gün depoladıkları Mythimna sequax yumurtalarının $T$. pretiosum ve T. atopovirilia türleri tarafindan parazitlendikten sonra gelişme sürelerinin kontrol grubuna göre daha uzun sürdüğünü gözlemlemişlerdir. T. atopovirilia türünde 60 ve 90 gün depolanan yumurtaların aynı sürede açıldığını fakat 30 gün depolananların onlara göre daha uzun sürede açıldığını,T. pretiosum'un da ise depolama süresi uzadıkça açılma sürelerinin kısaldığını, tespit etmişlerdir.

Özder ve Yaz (2016) T. pintoi tarafindan asalaklı olan yumurtaları farklı sıcaklıklarda $\left(0,4,8^{\circ} \mathrm{C}\right)$ ve farklı sürelerde $(1,2,3,4,5,6$ hafta boyunca) depolayarak, depolama sürelerinin uzaması ve sıcaklığın düşmesinin açılma süresini uzattı̆̆ııı bildirmişlerdir.

\subsection{Parazitlenen yumurtaların açılma sayısı}

Yürütülen çalışmada Trichogramma evanescens ve $T$. brassicae türleri tarafından parazitlenen yumurtaların açılma sayılarının depolama sürelerinden etkilendiği belirlenmiştir $(\mathrm{p}<0,05)$. Trichogramma evanescens tarafından 
parazitlenen yumurtalarda kontrolden sonra en çok açılan yumurta sayısının $30.40 \pm 1.65$ adet ile 3 hafta depolananlarda olduğu saptanmıştır. 2, 4 ve 5 hafta depolanan yumurtaların açılma sayıları arasında fark olmadığı en az çıkışın 1 hafta depolanan yumurtalarda görüldüğü tespit edilmiş̧ir.

Trichogramma brassicae tarafindan parazitlenenlerde ise, $31.70 \pm 1.12,30.20 \pm 1.83$ adet ile kontrolden sonra en çok açılan depolanmış yumurtalar 2 ve 3 depolanan yumurtalardır. haftalıklardır. En az açılma sayısı ise $12.50 \pm 2.88$ adet ile 1 hafta depolanan yumurtalarda görülmüştür (Tablo 1).

Greco ve Stilinovic (1998), Sitotroga cerealella yumurtalarını, sıvı nitrojende 20, 30 ve 130 gün depolamışlar ve Trichogramma pretiosum tarafindan parazitlenmiş tüm yumurtaların açılma oranlarını \%64'ün üzerinde bulmuşlardır.

Özder (2004) $0^{\circ} \mathrm{C}, 4^{\circ} \mathrm{C}$ ve $8^{\circ} \mathrm{C}$ de 31 güne kadar depoladığı E. kuehniella yumurtalarını, Trichogramma cacoeciae tarafindan parazitlendikten sonra $8^{\circ} \mathrm{C}^{\prime}$ de depolanmış olan yumurtaların açılma oranlarının, 3 haftadan sonra $\% 75$ in altına düştüğünü tespit etmiş̧tir.

Kara (2006) çalışmamıza benzer olarak parazitlemenin fazla olduğu türlerin açılma sayılarının da fazla olduğunu belirtmiştir.

Karabörklü ve Ayvaz (2007) $4^{\circ} \mathrm{C}^{\prime}$ de 10, 20, 30 ve 40 gün süresince depoladıkları E. kuehniella yumurtalarının $T$. evanescens tarafından parazitlendikten sonraki açılma oranlarının \%70 in üzerinde olduğunu en yüksek açılma oranının ise $\% 91.33$ ile 10 gün depolananlarda görüldüğünü bildirmiştir.

Krechemer ve Foerster (2016) 30, 60, 90 gün sivı azotta depoladıkları, M. sequax yumurtalarından T. pretiosum 'un parazitlediği tüm yumurtalarda çıkış görüldüğ̈̈nü tespit etmiştir. T. atopovirilia'da ise 30 ve 60 gün depolanmış yumurtaların hepsinin açılmasına rağmen, 90 günlük yumurtaların parazitlenen miktardan daha azının açıldığını bildirmişlerdir.

\subsection{Parazitlenen yumurtalardan çıkan dişi sayısı}

Dişi sayısının yüksek çıkması neslin devamı ve biyolojik mücadelenin sürekliliği için son derece önemlidir. Bu nedenle depolanmış yumurtalardan çıkış yapan bireylerin cinsiyetleri belirlenmiş ve sıvı azotta depolamanın cinsiyet dağılımına etkisi olduğu saptanmıştır ( $\mathrm{p}<0.05)$.

T. evanescens tarafindan parazitlenmiş olan yumurtaların açılması sonucu meydana gelen dişi sayısı, (kontrolden hariç) en yüksek $21.00 \pm 2.46,16.10 \pm 2.26,15.30 \pm 1.60$ ve $14.40 \pm 2.12$ adet ile $3,5,2$ ve 4 hafta depolanan yumurtalarda görülmüş̧ür.

En az dişi ise $6.40 \pm 1.75$ adet ile 1 hafta depolanmış yumurtalardan çıkmıştır. T. brassicae'nin parazitlediği yumurtalardan meydana gelen dişi sayısı ise $26.00 \pm 1.11$ ve $25.80 \pm 1.84$ adet ile 2 ve 3 hafta depolanan yumurtalarda en fazla bulunurken, $6.40 \pm 1.75$ adet ile 1 hafta depolanan yumurtalarda en olarak saptanmıştır. (Tablo 1).

Krechemer ve Foerster (2016) yürüttükleri çalşşmada sıvı azotta 30, 60 ve 90 gün depolanan yumurtaların Trichogramma sp. tarafindan parazitlenmesi sonucu açlan yumurtaların, araştırmamıza benzer şekilde dişi sayısının erkek sayısından yüksek olduğunu bildirmişlerdir.

Greco ve Stilinovic (1998) yürüttükleri çalışmada sıvı nitrojende depolanan yumurtalardan elde edilen erginlerin dişi cinsiyet oranını kontrol grubundan daha yüksek bulmuşlardır.

Karabörklü ve Ayvaz (2007) E. kuehniella ve S. cerealella yumurtalarını T. evanescens dişilerine parazitlettikten sonra, bu yumurtaların içerisinde gelişecek olan parazitoitleri farklı dönemlerinde $4^{\circ} \mathrm{C}$ 'de $10,20,30$ ve 40 gün süresince depolamışlardır. Parazitlenen yumurtalardan çıkan erginlerin yüzde olarak verilen dişi sayılarının kontrolden farklı olmadığını bildirmiş̧lerdir. Benzer şekilde Tezze ve Botto (2004) T. nerudai pupalarını $4^{\circ} \mathrm{C}$ 'de $25,50,75,100$, 125 ve 150 gün boyunca depoladıkları yumurtalardan çıkan yetişkinlerin dişi oranında farklılık olmadığını saptamışlardır. 
Tablo 1. Sivı nitrojende depolandiktan sonra Trichogramma evanescens tarafindan parazitlenen E. kuehniella Zell. (Un güvesi) yumurtalarında kararma süresi, parazitlenen yumurta sayısı, açılma süresi, açılma sayısı ve dişi saytsi

Table1.Trichogramma evanescen female longevity, eggs darkening time, number of parasitized eggs, opening time, opening number and number of female and parasitized eggs obtained from Ephestia kuehniella eggs stored in liquid nitrogen tank

\begin{tabular}{|c|c|c|c|c|c|}
\hline $\begin{array}{l}\text { Depolama } \\
\text { Süresi } \\
\text { (Hafta) }\end{array}$ & $\begin{array}{l}\text { Kararma } \\
\text { Süresi } \\
\text { (Gün) }\end{array}$ & $\begin{array}{l}\text { Parazitlene } \\
\text { Yumurta } \\
\text { Sayısı } \\
\text { (Adet) }\end{array}$ & $\begin{array}{c}\text { Parazitlenen } \\
\text { Yumurtaların } \\
\text { Açılma Süresi } \\
\text { (Gün) }\end{array}$ & $\begin{array}{c}\text { Parazitlenen } \\
\text { Yumurtalardan } \\
\text { Açılan Yumurta } \\
\text { Sayısı (Adet) }\end{array}$ & $\begin{array}{c}\text { Parazitlenen } \\
\text { Yumurtalardan } \\
\text { Çıkan } \\
\text { Dişi Sayısı } \\
\end{array}$ \\
\hline 1 & $4.50 \pm 0.16 \mathrm{~d}^{*}$ & $24.90 \pm 1.27 \mathrm{~d}$ & $10.40 \pm 0.16 \mathrm{c}$ & $10.80 \pm 1.78 \mathrm{~d}$ & $6.20 \pm 1.23 \mathrm{c}$ \\
\hline 2 & $4.00 \pm 0.14 \mathrm{bc}$ & $29.10 \pm 1.07 \mathrm{c}$ & $9.20 \pm 0.20 \mathrm{~b}$ & $23.90 \pm 1.58 \mathrm{c}$ & $15.30 \pm 1.60 \mathrm{~b}$ \\
\hline 3 & $3.70 \pm 0.15 \mathrm{~b}$ & $34.80 \pm 0.94 \mathrm{~b}$ & $8.80 \pm 0.13 \mathrm{~b}$ & $30.40 \pm 1.65 \mathrm{~b}$ & $21.00 \pm 2.46 \mathrm{~b}$ \\
\hline 4 & $4.20 \pm 0.13 \mathrm{~cd}$ & $25.10 \pm 1.71 \mathrm{~d}$ & $10.20 \pm 0.13 \mathrm{c}$ & $22.80 \pm 1.33 \mathrm{c}$ & $14.40 \pm 2.12 \mathrm{~b}$ \\
\hline 5 & $4.30 \pm 0.15 \mathrm{~cd}$ & $25.6 \pm 1.10 \mathrm{~cd}$ & $10.20 \pm 0.13 \mathrm{c}$ & $25.00 \pm 0.96 \mathrm{c}$ & $16.10 \pm 2.26 \mathrm{~b}$ \\
\hline Kontrol & $3.10 \pm 0.10 \mathrm{a}$ & $40.00 \pm 1.27 \mathrm{a}$ & $8.20 \pm 0.12 \mathrm{a}$ & $37.90 \pm 1.65 \mathrm{a}$ & $27.70 \pm 3.38 \mathrm{a}$ \\
\hline
\end{tabular}

* Her sütundaki aynı küçük harf ile gösterilen rakamlar arasındaki istatiksel fark önemsizdir ( $<<0.05)$.

Tablo 2. Sivı nitrojende depolandıktan sonra Trichogramma brasssicae tarafindan parazitlenen E. kuehniella Zell. (Un Güvesi) yumurtalarında kararma süresi, parazitlenen yumurta sayısı, açılma süresi, açılma sayısı ve dişi sayısı.

Table 2. Trichogramma brasssicae female longevitiy, eggs darkening time, number of parasitized eggs, opening time, opening number and number of female and parasitized eggs obtained from Ephestia kuehniella eggs stored in liquid nitrogen tank

\begin{tabular}{cccccc}
\hline $\begin{array}{c}\text { Depolama } \\
\text { Süresi } \\
\text { (Hafta) }\end{array}$ & $\begin{array}{c}\text { Kararma } \\
\text { Süresi } \\
\text { (Gün) }\end{array}$ & $\begin{array}{c}\text { Parazitlenen } \\
\text { Yumurta } \\
\text { Sayısı (Adet) }\end{array}$ & $\begin{array}{c}\text { Parazitlenen } \\
\text { Yumurtaların } \\
\text { Açılma Süresi } \\
\text { (Gün) }\end{array}$ & $\begin{array}{c}\text { Parazitlenen } \\
\text { Yumurtalardan } \\
\text { Açlan Yumurta } \\
\text { Sayısı (Adet) }\end{array}$ & $\begin{array}{c}\text { Parazitlenen } \\
\text { Yumurtalardan } \\
\text { Çıkan } \\
\text { Dişi Sayısı }\end{array}$ \\
\hline 1 & $4.60 \pm 0.16 \mathrm{c} *$ & $20.40 \pm 1.68 \mathrm{~d}$ & $10.70 \pm 0.21 \mathrm{c}$ & $12.50 \pm 2.88 \mathrm{~d}$ & $6.40 \pm 1.75 \mathrm{c}$ \\
2 & $3.80 \pm 0.20 \mathrm{~b}$ & $34.10 \pm 1.07 \mathrm{~b}$ & $9.50 \pm 0.22 \mathrm{~b}$ & $31.70 \pm 1.12 \mathrm{a}$ & $26.00 \pm 1.11 \mathrm{a}$ \\
3 & $3.40 \pm 0.13 \mathrm{ab}$ & $35.7 \pm 0.96 \mathrm{ab}$ & $9.30 \pm 0.15 \mathrm{~b}$ & $30.20 \pm 1.83 \mathrm{ab}$ & $25.80 \pm 1.84 \mathrm{a}$ \\
4 & $4.40 \pm 0.16 \mathrm{c}$ & $26.80 \pm 1.34 \mathrm{c}$ & $9.60 \pm 0.16 \mathrm{~b}$ & $25.00 \pm 1.77 \mathrm{c}$ & $20.10 \pm 1.55 \mathrm{~b}$ \\
5 & $4.40 \pm 0.16 \mathrm{c}$ & $27.80 \pm 0.86 \mathrm{c}$ & $10.40 \pm 0.16 \mathrm{c}$ & $25.50 \pm 0.81 \mathrm{bc}$ & $19.60 \pm 1.25 \mathrm{~b}$ \\
Kontrol & $3.00 \pm 0.01 \mathrm{a}$ & $38.60 \pm 1.08 \mathrm{a}$ & $8.50 \pm 0.16 \mathrm{a}$ & $33.60 \pm 1.02 \mathrm{a}$ & $28.80 \pm 1.32 \mathrm{a}$ \\
\hline
\end{tabular}

* Her sütundaki aynı küçük harf ile gösterilen rakamlar arasındaki istatiksel fark önemsizdir ( $\mathrm{p}<0,05)$.

\subsection{Depolanmış E. kuehniella Yumurtalarından Elde Edilen Parazitoitlerin Performansı}

\section{8. Ömür uzunluklart}

Sıvı nitrojende 4 ve 5 hafta depolandıktan sonra Trichogramma evanescens'in parazitlemiş olduğu yumurtalardan çıkan dişilerin ömür uzunluklarının, kontrol grubu dişilerinin ömründen istatiksel olarak farklı olmadığı tespit edilmiştir $(\mathrm{p}<0.05)$. En kısa süre yaşayan dişilerin ise $13.10 \pm 0.91$ ve $15.20 \pm 0.86$ gün ile 1 ve 2 hafta depolanan yumurtalardan çıkan dişiler olduğu belirlenmiştir (Tablo 3).

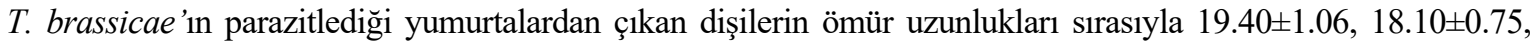

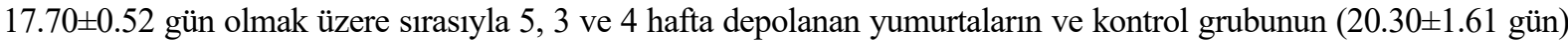
en uzun süre yaşamış olduğu istatistiksel olarak belirlenmiştir. T. brassicae'nın parazitlediği yumurtalardan meydana gelen dişilerden en kısa süre hayatta kalanlar $12.30 \pm 0.76$ gün ile 1 hafta depolanmış yumurtalardan çıkanlar olmuştur $(\mathrm{p}<0.05$, Tablo 4). 
Jajali ve Singh (1992) konukçu Corcyra cephalonica yumurtalarını kullanarak 4 Trichogramma türünün farklı biyolojik evrelerinde 2,5 ve $10^{\circ} \mathrm{C}$ 'de 7 ila 49 gün boyunca depolayarak yaptıkları araştırmada. Pupa evresinde depolanan parazitoitlerin, ömür uzunluğunun $2^{\circ} \mathrm{C}$ 'de 14 güne, $5^{\circ} \mathrm{C}$ ve $10^{\circ} \mathrm{C}$ de ise 21 güne kadar istikrarlı bir şekilde devam ettiğini daha sonra azaldığını tespit etmiş̧lerdir.

Özder ve Tayat (2018) sıvı nitrojende farklı sürelerde depoladıkları E. kuehniella yumurtalarından elde ettikleri $T$. pintoi dişilerinde en kısa ömrün 6.30 \pm 0.22 gün olarak 6 hafta süre ile depolanmış yumuttalardan elde edilen bireylerde görüldüğünü kaydetmişlerdir.

Özder (2004) Ephestia kuehniella yumurtalarını $0^{\circ} \mathrm{C}, 4^{\circ} \mathrm{C}$ ve $8^{\circ} \mathrm{C}$ 'de 31 güne kadar depolayarak yürüttüğü çalışmada depolanan yumurtalardan çıkan parazitoit, Trichogramma cacoeciae'nin ömrünün en uzun 15 gün olduğunu ve $4^{\circ} \mathrm{C}$ 'de 1 hafta depolanan yumurtalarda görüldüğünü saptamıştır.

Özder ve Yaz (2016) T. pintoi tarafindan asalaklı olan yumurtaları farklı sıcaklıklarda $\left(0,4,8^{\circ} \mathrm{C}\right)$ ve farklı sürelerde $(1,2,3,4,5,6$ hafta boyunca) depolayarak yürüttükleri çalışmada depolanmış yumurtalardan elde edilen dişilerin ömrünün depolama süresi uzadıkça kısaldığını, sıcaklık arttıkça uzadığını belirlemişlerdir.

\subsection{Parazitlenen yumurtaların kararma süresi}

Depolanmış Ephestia kuehniella yumurtalarından çıkan T. evanescens dişilere yaşadıkları süre boyunca her gün taze E. kuehniella yumurtası verilip yumurtaların soğukta depolanmasının parazitoit neslinin devamına etkileri araştırılmış ve aralarındaki fark önemli bulunmuştur $(\mathrm{p}<0.05)$. Sıvı nitrojende 5 hafta boyunca depolanmış yumurtaların $T$. evanescens tarafindan parazitlenmesi sonucu meydana gelen dişilerin, parazitlediği yumurtaların $3.57 \pm 0.35$ gün ile en kısa sürede kararmış olduğu tespit edilmiştir. En geç kararanlar, $4.08 \pm 0.44$ gün ile 4 hafta depolanan yumurtalardan çıkan dişilerin parazitlediği yumurtalar olmuştur (Tablo 3).

T. brassicae dişileri tarafından parazitlenen yumurtalardan kontrol grubundan sonra en kısa sürede kararan $3.38 \pm 0.46$ gün ile 1 hafta sıvı azotta depolanan yumurtalardan çıkan dişilerin parazitlediği yumurtalar olmuştur. En uzun sürede kararanların ise $4.26 \pm 0.39$ ve $3.61 \pm 0.36$ gün ile 5 ve 4 hafta depolanan yumurtalardan çıkan dişilerin parazitlediği yumurtalar olduğu tespit edilmiştir ( $\mathrm{p}<0.05$, Tablo 4$)$.

Özder ve Yaz (2016) T. pintoi tarafindan asalaklı olan yumurtaları farklı sıcaklıklarda $\left(0,4,8^{\circ} \mathrm{C}\right)$ ve farklı sürelerde $(1,2,3,4,5,6$ hafta boyunca) depolayarak elde ettikleri dişilere günlük E.kuehniella yumurtaları vererek parazitletmiş ve parazitlenen yumurtaların kararma sürelerini incelemiştir. Soğukta depolamanın, dişilerin nesil devamlılığına etkisi olduğunu belirlemişlerdir. Asalaklı olarak depolanmış yumurtaların depolanma sıcaklığı arttıkça, ergin hale geldiklerinde parazitledikleri yumurtaların kararma sürelerinin kısaldığını, aynı sıcaklıkta ise depolama süresi arttıkça kararma sürelerinin uzadığını bildirmişlerdir.

\subsection{Parazitlenen yumurta saytst}

Yürütülen çalışmada en çok parazitlemenin, 5 ve 3 hafta depolanmış yumurtalardan elde edilen T. evanescens dişileri tarafindan, sırasıyla $217.70 \pm 5.32$ ve $207.40 \pm 11.62$ adet olarak, en az parazitlemenin ise 2 hafta süreyle depolanan yumurtalardan çıkan dişiler tarafından 127.0 \pm 8.94 adet olarak gerçekleştirildiği belirlenmiştir $(\mathrm{p}<0.05$, Tablo 3). 3 ve 5 hafta depolanmış yumurtalardan çıkan T. brassicae dişilerinin, $192.80 \pm 10.09$ ve $192.70 \pm 7.94$ adet olmak üzere ömürleri boyunca en çok parazitlemeyi gerçekleştirdikleri ve aralarında istatistiki açıdan fark olmadığı saptanmıştır. T. brassicae tarafindan, en az parazitlemenin ise $122.70 \pm 7.35$ adet ile 1 hafta depolanmış yumurtalardan çıkan dişilerin gerçekleştirdiği tespit edilmiştir (Tablo 4).

Karabörklü ve Ayvaz (2007) E. kuehniella ve S. cerealella yumurtalarını T. evanescens dişilerine parazitlettikten sonra bu yumurtaların içerisinde gelişecek olan parazitoitleri yumurta döneminde $4^{\circ} \mathrm{C}$ 'de $10,20,30$ ve 40 gün süresince depolamışlardır. İki konukçuda da depolanan yumurtalardan çıkan ergin dişilerin parazitleme performansının 10 ve 20 gün depolananlarda kontrolden farklı olmadığını 30 ve 40 gün depolananlarda ise daha düşük olduğunu bildirmişlerdir.

Güven (2008) yaptı̆̆ı çalışmalarda, depolamanın parazitoit performansına etkili olduğunu belirterek, depolama süresi arttıkça parazitlenen yumurta sayısının azaldığını kaydetmiştir. 
Özder ve Yaz (2016) T. pintoi tarafindan asalaklı olan yumurtaları farklı sicaklıklarda $\left(0,4,8^{\circ} \mathrm{C}\right)$ ve farklı sürelerde $(1,2,3,4,5,6$ hafta boyunca) depolayarak, depolanmış yumurtalardan çıkan dişilerin, parazitlediği yumurta sayılarını saptamışlardır. En yüksek parazitlemenin $86 \pm 0.87$ adet ile $8^{\circ} \mathrm{C}^{\prime}$ de 1 hafta depolanmış yumurtalarda, en düşük parazitlemenin ise $40.98 \pm 0.61$ adet ile $0^{\circ} \mathrm{C}^{\prime}$ de 6 hafta depolanan yumurtalarda görüldüğünü tespit etmişlerdir.

\subsection{Parazitlenen yumurtaların açılma süresi}

Yapılan çalışmada depolanan yumurtalardan çıkan dişilerin parazitlediği yumurtalar, detaylı bir şekilde incelenmiş ve parazitlenme gününden ilk ergin çıkışı görülene kadar geçen süreler hesaplanmıştır. T. evanescens türünde en kısa sürede açılma $9.10 \pm 0.54$ gün ile 1 hafta depolanmış yumurtalardan çıkan dişilerin parazitlediği yumurtalarda görülmüştür. En uzun sürede açılma ise $10.50 \pm 0.35$ gün ile 4 hafta depolanmış yumurtalardan çıkan dişilerin parazitlediği yumurtalarda görülmüştür ( $\mathrm{p}<0.05$, Tablo 3 ).

Sıvı azotta depolanmış yumurtalardan çıkan $T$. brassicae dişilerinin, parazitlediği yumurtaların açılma süresi, en kısa $8.67 \pm 0.58$ gün olup, 1 hafta depolananlarda görülmüştür. En uzun açılma süresi ise $10.86 \pm 0.48$ gün ile 5 hafta depolananlardan elde edilen dişilerin parazitlediği yumurtalarda görülmüştür ( $\mathrm{p}<0.05$, Tablo 4 ).

\subsection{Parazitlenen yumurtaların açılma sayısı}

Sıvı azotta depolanmış yumurtalardan meydana gelen, T. evanescens dişilerinin ömürleri boyunca parazitlediği yumurtalardan en fazla ergin çıkışııın, 5 ve 3 hafta depolanan yumurtalardan çıkan dişilerin parazitlediği yumurtalarda olduğu tespit edilmiştir. 1 ve 2 hafta süreyle depolanmış yumurtalardan çıkan dişilerin ömürleri boyunca parazitlediği yumurtalarda sırasıyla $119.0 \pm 8.54$ ve $121.7 \pm 8.93$ adet ile en az açılma görülmüştür ( $<<0.05$, Tablo 3). T. brassicae' in ömrü boyunca parazitlediği yumurtalardan kontrolden sonra en çok ergin çıkışı $184.90 \pm 7.81$ ve $184.0 \pm 10.26$ adet ile 5 ve 3 hafta depolanan yumurtalardan çıkan dişilerin parazitlediği günlük yumurtalarda görülmüştür. En az ergin çıkışın ise $114.60 \pm 7.21$ adet ile 1 hafta süreyle depolanan yumurtalardan çıkan dişilerin parazitlediği yumurtalarda olduğu belirlenmiştir $(\mathrm{p}<0.05$, Tablo 4$)$.

\subsection{Parazitleneni yumurtalardan çıkan dişi sayısı}

Yürütülen çalışmada depolanan yumurtaların T. evanescens tarafindan parazitlenmesi sonucu elde edilen dişilerin, ömürleri boyunca parazitlediği yumurtalardan çıkan dişi sayısı da incelenmiştir. En fazla dişinin $115.60 \pm 6.98$ adet ile 3 hafta depolanmış yumurtalardan çıkan dişiler tarafindan parazitlenen yumurtalardan meydana geldiği ve kontrol

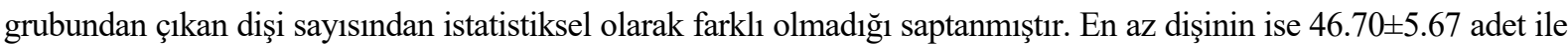
1 hafta azot tankında depolanmış olan yumurtalardan çıkan dişi parazitoitlerin parazitlediği yumurtalardan meydana geldiği görülmüştür ( $\mathrm{p}<0.05$, Tablo 3). T.brassicae'nın parazitlemiş olduğu 3 haftalık yumurtalardan meydana gelen dişilerin parazitlediği yumurtalarda $98.60 \pm 5.40$ adet ile en fazla dişi çıkışı görülürken, 2 haftalık yumurtalardan çıkan dişilerin parazitlediği yumurtalardan 61.40 5.85 adet ile en az dişi çıkışı olduğu saptanmıştır (Tablo 4).

Doetzer ve Foerster (2013) Pentatomidae yumurtalarını sıvı azotta depoladıktan sonra ilk olarak Trissolcus basalis ve Telenomus podisi türlerinin depolanan yumurtaların parazitlemesini değerlendirmişlerdir. Çalışmanın devamında ise sıvı azotta depolanan konakçı yumurtalarda geliştirilen yetişkin parazitoitlerde uyku halini araştırmak amacıyla $T$. basalis ve $T$. podisi dişilerini $18^{\circ} \mathrm{C}^{\prime}$ de 120 ve 180 gün uykuda tutulmuşlardır. Sonuç olarak $18^{\circ} \mathrm{C}^{\prime}$ de depolama süresinin $T$. basalis' in cinsiyet dağılımını etkilenmemiş olduğunu, T. podisi'nin ise hem azottaki depolanma süresinden, hem de $18^{\circ} \mathrm{C}$ 'de depolanma süresinden etkilemiş olduğunu bildirerek, bu iki yönteminde dişi sayısının yüksek çıkmasından dolayı birlikte kullanılmasının avantajı olacağını öne sürmüşlerdir. 
JOTAF/ Journal of Tekirdag Agricultural Faculty, 2020, 17(3)

Tablo 3. Sivı azotta depolanan Ephestia kuehniella Zell. (Un güvesi) yumurtalarının Trichogramma evanescens tarafindan parazitlenmesi sonucu elde edilen dişilerin ömür uzunlukları, yaşadıkları süre boyunca her gün ortalama olarak parazitledikleri yumurtaların sayısı, kararma günü, açılma günü, açılma sayısı ve parazitlenen yumurtalardan meydana gelen dişi sayısı.

Table3. Trichogramma evanescen obtained from Ephestia kuehniella eggs stored in liquid nitrogen tank female longevity, eggs darkening time, number of parasitized eggs, opening time, opening number and number of female and parasitized eggs obtained

\begin{tabular}{ccccccc}
\hline $\begin{array}{l}\text { Depolama } \\
\text { Süresi } \\
\text { (Hafta) }\end{array}$ & $\begin{array}{c}\text { Ömür } \\
\text { Uzunluğu } \\
\text { (Gün) }\end{array}$ & $\begin{array}{c}\text { Kararma } \\
\text { Süresi } \\
\text { (Gün) }\end{array}$ & $\begin{array}{c}\text { Parazitlenen } \\
\text { Yumurta } \\
\text { Sayısı (Adet) }\end{array}$ & $\begin{array}{c}\text { Parazitlenen } \\
\text { Yumurtaların } \\
\text { Açıa Süresi } \\
\text { (Gün) }\end{array}$ & $\begin{array}{c}\text { Parazitlenen } \\
\text { Yumurtalardan } \\
\text { Açılan } \\
\text { Yumurta Sayısı } \\
\text { (Adet) }\end{array}$ & $\begin{array}{c}\text { Parazitlenen } \\
\text { Yumurtalardan } \\
\text { Çıkan } \\
\text { Bireylerde } \\
\text { Dişi Sayısı }\end{array}$ \\
\hline 1 & $13.10 \pm 0.91 \mathrm{c}$ & $3.74 \pm 0.45 \mathrm{c}$ & $132.8 \pm 9.12 \mathrm{~d}$ & $9.10 \pm 0.57 \mathrm{e}$ & $119.0 \pm 8.54 \mathrm{~d}$ & $46.70 \pm 5.67 \mathrm{~d}$ \\
2 & $15.20 \pm 0.86 \mathrm{c}$ & $3.90 \pm 0.53 \mathrm{~b}$ & $127.0 \pm 8.94 \mathrm{e}$ & $9.81 \pm 0.51 \mathrm{~b}$ & $121.7 \pm 8.93 \mathrm{~d}$ & $68.20 \pm 7.47 \mathrm{c}$ \\
3 & $19.11 \pm 0.63 \mathrm{~b}$ & $3.81 \pm 0.49 \mathrm{bc}$ & $207.40 \pm 11.62 \mathrm{~b}$ & $9.24 \pm 0.42 \mathrm{~d}$ & $199.2 \pm 11.07 \mathrm{~b}$ & $115.60 \pm 6.98 \mathrm{a}$ \\
4 & $19.45 \pm 0.05 \mathrm{ab}$ & $4.08 \pm 0.44 \mathrm{a}$ & $159.80 \pm 6.44 \mathrm{c}$ & $10.50 \pm 0.35 \mathrm{a}$ & $149.9 \pm 6.02 \mathrm{c}$ & $90.30 \pm 4.96 \mathrm{~b}$ \\
5 & $20.40 \pm 0.56 \mathrm{ab}$ & $3.57 \pm 0.35 \mathrm{~d}$ & $217.70 \pm 5.32 \mathrm{~b}$ & $9.53 \pm 0.41 \mathrm{c}$ & $205.9 \pm 6.46 \mathrm{~b}$ & $77.20 \pm 7.25 \mathrm{bc}$ \\
Kontrol & $22.00 \pm 1.06 \mathrm{a}$ & $3.35 \pm 0.32 \mathrm{e}$ & $243.4 \pm 8.61 \mathrm{a}$ & $8.57 \pm 0.36 \mathrm{f}$ & $229.5 \pm 7.67 \mathrm{a}$ & $117.30 \pm 8.95 \mathrm{a}$ \\
\hline
\end{tabular}

* Her sütundaki aynı küçük harf ile gösterilen rakamlar arasındaki istatiksel fark önemsizdir $(\mathrm{p}<0.05)$.

Tablo 4. Sıvı azotta depolanan Ephestia kuehniella Zell. (Un Güvesi) yumurtalarının Trichogramma brassicae tarafindan parazitlenmesi sonucu elde edilen dişilerin ömür uzunlukları. yaşadıkları süre boyunca her gün ortalama olarak parazitledikleri yumurtaların sayısı. kararma günü açılma günü. açılma sayısı ve parazitlenen yumurtalardan meydana gelen dişi sayısı.

Table 4. Trichogramma brassicae obtained from Ephestia kuehniella eggs stored in liquid nitrogen tank female longevity. eggs darkening time. number of parasitized eggs. opening time. opening number and number offemale and parasitized eggs obtained

\begin{tabular}{ccccccc}
\hline $\begin{array}{c}\text { Depolama } \\
\text { Süresi } \\
\text { (Hafta) }\end{array}$ & $\begin{array}{c}\text { Ömür } \\
\text { Uzunluğu } \\
\text { (Gün) }\end{array}$ & $\begin{array}{c}\text { Kararma } \\
\text { Süresi } \\
\text { (Gün) }\end{array}$ & $\begin{array}{c}\text { Parazitlenen } \\
\text { Yumurta } \\
\text { Sayısı } \\
\text { (Adet) }\end{array}$ & $\begin{array}{c}\text { Parazitlenen } \\
\text { Yumurtaların } \\
\text { Açılma Süresi } \\
\text { (Gün) }\end{array}$ & $\begin{array}{c}\text { Parazitlenen } \\
\text { Yumurtalardan } \\
\text { Açılan } \\
\text { Yumurta Sayısı } \\
\text { (Adet) }\end{array}$ & $\begin{array}{c}\text { Parazitlenen } \\
\text { Yumurtalardan } \\
\text { Çıan }\end{array}$ \\
$\begin{array}{c}\text { Bireylerde } \\
\text { Dişi Sayısı }\end{array}$ \\
\hline 1 & $12.30 \pm 0.76 \mathrm{c}$ & $3.38 \pm 0.46 \mathrm{~b}$ & $122.70 \pm 7.35 \mathrm{c}$ & $8.67 \pm 0.58 \mathrm{a}$ & $114.6 \pm 7.21 \mathrm{~d}$ & $76.4 \pm 6.04 \mathrm{~cd}$ \\
2 & $16.90 \pm 1.00 \mathrm{c}$ & $3.50 \pm 0.38 \mathrm{c}$ & $159.70 \pm 12.87 \mathrm{~b}$ & $9.61 \pm 0.40 \mathrm{c}$ & $160.9 \pm 12.7 \mathrm{~b}$ & $61.40 \pm 5.85 \mathrm{~d}$ \\
3 & $18.10 \pm 0.75 \mathrm{~b}$ & $3.49 \pm 0.39 \mathrm{c}$ & $192.80 \pm 10.09 \mathrm{a}$ & $9.47 \pm 0.38 \mathrm{~b}$ & $184.0 \pm 10.26 \mathrm{ab}$ & $98.60 \pm 5.40 \mathrm{ab}$ \\
4 & $17.70 \pm 0.52 \mathrm{ab}$ & $3.61 \pm 0.36 \mathrm{~d}$ & $133.0 \pm 9.39 \mathrm{bc}$ & $10.50 \pm 0.38 \mathrm{~d}$ & $127.8 \pm 3.88 \mathrm{c}$ & $83.80 \pm 3.58 \mathrm{bc}$ \\
5 & $19.40 \pm 1.06 \mathrm{ab}$ & $4.26 \pm 0.39 \mathrm{~d}$ & $192.70 \pm 7.94 \mathrm{a}$ & $10.86 \pm 0.48 \mathrm{e}$ & $184.9 \pm 7.81 \mathrm{ab}$ & $87.50 \pm 6.19 \mathrm{bc}$ \\
Kontrol & $20.30 \pm 1.61 \mathrm{a}$ & $3.24 \pm 0.33 \mathrm{a}$ & $219.80 \pm 11.8 \mathrm{a}$ & $8.64 \pm 0.39 \mathrm{a}$ & $203.2 \pm 11.34 \mathrm{a}$ & $107.4 \pm 8.52 \mathrm{a}$ \\
\hline
\end{tabular}

* Her sütundaki aynı küçük harf ile gösterilen rakamlar arasındaki istatiksel fark önemsizdir ( $\mathrm{p}<0.05)$.

\section{Sonuç}

Trichogramma türleri ile biyolojik mücadelenin etkin bir şekilde gerçekleşebilmesi için salım zamanının doğru seçilmesi ve o süre içerisinde fazla sayıda ergin üretiminin gerçekleşmesi gerekmektedir. Bu süreçte konukçu yetersizliğinden kaynaklanacak aksaklıkları gidermek ve hazırda konukçu yumurtası bulundurmak amacıyla birçok depolama çalışılması yürütülmüş ve yürütülmektedir (Bernad ve ark.,2000; Karabörklü ve Ayvaz 2007).

Yapılan bu çalışmada. 6 hafta depolanmış yumurtalarda hiç kararma ve dolayısıyla parazitlenme olmamamsı Lohman ve ark. (2007) ve St-onge ve ark. (2016) çalışmalarındaki gibi sıvı azotun Ephestia kuehniella yumurtaları için uzun süreli uygun depolama yöntemi olmadığını yumurtaların içerisindeki konukçu embriyosunun donarak kristalleşip yumurta çeperine zarar verdiğini düşündürmüştür.

Araştırmanın sonucunda. 5 hafta süre ile sıvı azotta depolanmış E. kuehniella yumurtalarının Trichogramma evanescens Westwood ve Trichogramma brassicae Bezdenko tarafından başarılı bir şekilde parazitlenebildiği. 6 

üretimlerinin araştırılması

hafta süre ile depolanmış yumurtalarda parazitlemenin hiç gerçekleşmediği saptanmıştır. Ancak her iki tür içinde sıvı azotta depolanmış E. kuehniella yumurtalarının hem parazitlenme sayısı. açılma sayısı ve dişi sayısı hem de sıvı azotta depolanmış yumurtalardan elde edilen dişi parazitoitlerin performansı açısından. 3 hafta depolama süresinin için en uygun süre olduğu saptanmıştır. Biyolojik mücadeleye yönelik çalışmalarda kısa süreli depolamalar için bu yöntemin başarı ile kullanılabilir.

\section{Teşekkür}

Bu çalışma Tekirdağ Namık Kemal Üniversitesi tarafından NKUBAP.03.YL.19.198 Nolu Araştırma Projesi olarak desteklenmiştir. 


\section{Kaynakça}

Ay, R. (1994). Değişik yöntemlerle embriyosu öldürülmüs Ephestia kuehniella Zeller (Lepidoptera: Pyralidae) yumurtalarında Trichogramma turkeiensis Kostadinov ve T. embryophagum (Hartig) (Hymnoptera. Trichogrammatidae)'un yetiştrilmesi üzerine araştırmalar. (Yüksek Lisans Tezi) Ankara Üniversitesi Fen Bilimleri Enstitüsü Bitki Koruma Anabilim Dalı. Ankara.

Bernardi, E. B., Haddad, M. L., Parra, J. R. P. (2000). Comparison of artificial diets for rearing Corcyra cephalonica (Stainton. 1865) (Lep.: Pyralidae) for Trichogramma mass production. Rev. Brasil Biol.. 60. 45-52.

Bulut, H. (1990). Yumurta parazitoiti Trichogramma türleri için uygun konukçu yumurtası yaşının belirlenmesi ve erginlerin bazı davranışları üzerine araștırmalar. Türkiye II. Biyolojik Mücadele Kongresi Bildirileri. Ankara Ünv. Ziraat Fak. Bitki Koruma Bölümü. Ankara. $37-51$.

Bulut, H. . Kılınçer. N. (1987). Yumurta paraziti Trichogramma spp. (Hymenoptera: Trichogrammatidae)'in un güvesi (Ephestia kuehniella Zell.) (Lepidoptera: Pyralidae) yumurtalarında üretimi ve konukçu-parazit ilişkileri. Türkiye I. Entomoloji Kongresi Bildirileri. Izmir.

Doetzer, A. K., Foerster, L. A. (2013). Storage of Pentatomid eggs in liquid nitrogen and dormancy of Trissolcus basalis (Wollaston) and Telenomus podisi Ashmead (Hymenoptera: Platygastridae) adults as a method of mass production. Neotrop Entomol. 13(42). 534-538.

Greco, C. F. ve Stilinovic. D. (1998). Parasitization performance of Trichogramma spp. (Hym.. Trichogammatidae) reared on eggs of Sitotroga cerealella Oliver (Lep.. Gelechiidae). stored at freezing and subfreezing conditions. J Appl Entomol 122: 311-314.

Güven, A. (2008). Düşük slcaklıklarda depolanan Cadra (Ephestia) cautella Walk. (Lep.. Pyralidae) yumurtaları üzerinde yetiştirilen Trichogramma cacoeciae Marchal. T. brassicae Bezdenko ve T. evanescens Westwood'un (Hym.. Trichogrammatidae) bazl biyolojik özellikleri. (Yüksek Lisans Tezi) Namık Kemal Üniversitesi Fen Bilimleri Enstitüsü. Tekirdağ.

Jalali, S. K., Singh, S. P. (1992). Differential response of four Trichogramma species to low temperatures for short term storage. Entomophaga. 37(1). 159-165.

Kara, G. (2006). Cadra (Ephestia) cautella Walk ve Ephestia kuehniella Zell. (Lepidoptera: Pyrallidae) ile yumurta parazitoitleri Trichogramma brassicae Bedzenko. Trichogramma cacoeciae Marchal ve Trichogramma evanescens Westwood (Hymenoptera: Trichogrammatidae) arasındaki biyolojik ilişkiler. (Yüksek Lisans Tezi) Namık Kemal Üniversitesi. Fen Bilimleri Enstitüsü. Tekirdağ.

Karabörklü, S., Ayvaz. A. (2007). Soğukta depolamanın farklı konukçularda yetişen Trichogramma evanescens Westwood (Hym: Trichogrammatidae)'in farklı evreleri üzerine etkileri. Erciyes Üniversitesi Fen Bilimleri Enstitüsü Dergisi. 23 (1-2) 30 - 36.

Krechemer, F., Foerster. L. (2016). Mass production of Trichogramma spp. using Mythimna sequax eggs stored in liquid nitrogen. BioControl. 61(5). 497-505.

Lohmann. T. . Martınanazzo. T. . Pietrowskı. V. . Gibbert. F. . Kraemer. B. (2007). Viability of the egg storage of Anagasta kuehniella. Zeller (Lepidoptera: Pyralidae) in liquid nitrogen for the production of Trichogramma pretiosum. Riley (Hymenoptera: Trichogrammatidae). Resumos do V CBA - Outras temáticas.2(2).

Özder, N. (2002). Parasitization performance of Trichogramma cacoeciae. T. evanescens and T. brassicae (Hym: Trichogrammatidae) reared on the embryos of Ephestia kuehniella Zell. (Lep: Pyralidae) killed by freezing. The Great Lakes Entomologist. 35:107-112.

Özder, N. (2004). Effect of differet cold storage periods on parasitization performance of Trichogramma cacoeciae (Hymenoptera: Trichogrammatidae) on eggs of Ephestia kuehniella (Lepidoptera:Pyralida). Biocontrol Science and Technology. 14(5). 441-447.

Özder, N. (2006). Effect of cold storage of adult Trichogramma brassicae. T. cacoeciae and T. evanescens (Hym.: Trichogrammatidae). Archives of Phytopathology and Plant Protection. 41(4). 296-299.

Özder, N., Tayat, E. (2018). Sıvı azotta depolanmış Ephestia kuehniella Zeller yumurtalarını kullanarak Trichogramma pintoi Voegele'nin kitle üretimi. Tekirdağ Ziraat Fakültesi Dergisi 15(02).

Smith, S. M. (1996). Biological control with Trichogramma advances. successes. and potential of their use. Annual Review of Entomology. 41. $375-406$.

St-Onge, M., Cormier, D., Todorova, S. ve Lucas. E. (2016). Conservation of Ephestia kuehniella eggs as hosts for Trichogramma ostriniae. $J$ Appl Entomol 140:218-222.

Tezze, A. A . ve Botto, E. N. (2004). Effect of cold storage on the quality of Trichogramma nerudai (Hymenoptera: Trichogrammatidae). Biological Control. 30. 11-16.

Yaz, M., Özder, N. (2016). Trichogramma pintoi Voegele tarafından parazitlenmiş Ephestia kuehniella Zeller yumurtalarının farklı sıcaklıklarda depolanması üzerine araştırmalar. Tekirdağ Ziraat Fakültesi Dergisi. 13 (03). 165-174. 